\title{
A framework for research on e-learning assimilation in SMEs: A strategic perspective
}

\section{Structured Abstract:}

- Purpose: This study proposes an integrative conceptual framework of e-learning adoption and assimilation that is adapted to the specific context of SMEs.

- Design/methodology/approach: We review the literature on the state of e-learning usage in SMEs and on the IT adoption and assimilation factors that can be specifically applied to e-learning adoption and assimilation in this context. We then integrate these factors within a research framework, and formulate a set of twenty propositions.

- Findings: We identify the technological, organizational and environmental factors that are likely to favour or hinder e-learning adoption and assimilation in SMEs, as well as the interaction among these factors.

- Research limitations/implications: The integrative framework and the seventeen propositions that emanate from it constitute the conceptual foundation for a research program and hypotheses on the adoption and assimilation of e-learning in SMEs.

- Practical implications: This study offers managers a frame of reference to analyze their firm's situation before initiating an e-learning program by highlighting key adoption and assimilation factors in the specific context of SMEs.

Keywords: e-learning; IT adoption; IT assimilation; SME. 


\section{Introduction}

Many industrialized countries are undergoing industrial reorganizations leading them towards knowledge-based economies in which training activities play a crucial role. Leveraging the massive development of information technologies (IT), organizations adopt an e-learning approach in order to align themselves with the requirements of a knowledge-based economy. Accepted by most training professionals as a credible training strategy, e-learning has been growing in popularity since the end of the 1990s (Bell, Martin, and Clarke, 2004; Nisar, 2002). The e-leaning market represents a sizeable portion of the training industry: worldwide, $\$ 90$ billion are spent in training, with $\$ 20$ billion spent on e-learning (Garavan, Carbery, O’Malley, and O'Donnell, 2010). However, the adoption, diffusion and exploitation of e-learning by both educational institutions and organizations has proven to be slower than one would have anticipated, given the revolution in vocational training that was expected from e-learning (Bell et al., 2004).

In spite of the low level of adoption in organizations, e-learning is still depicted as an attractive complement or even an alternative to traditional training methods (Long and Smith, 2004), especially for small and medium-sized businesses (SMEs), considering the time and resources constraints faced by these organizations (Moon, Birchall, Williams, and Vrasidas, 2005) and their need for "support of immediate problem solving at work" (Admiraal and Lockhorst, 2009, p. 744). Yet, the literature on the usage pattern of e-learning by SMEs paints a rather bleak picture (Beer, Hamburg, and Paul, 2006; Hamburg and Hall, 2008; Sambrook, 
2003). What factors then explain this apparent contradiction? What factors are likely to help or hinder e-learning adoption, diffusion and exploitation in SMEs? In previous research, several reasons were put forward, some related to the paucity of IT infrastructure (Admiraal and Lockhorst, 2009; Sambrook, 2003), others to an inadequate e-learning offer (Caskey, 2007; Hardaker, Dockery, and Sabki, 2007) or to the specificity of SMEs' culture (Hardaker et al., 2007) and their managers' attitudes towards e-learning solutions or to their being unconvinced of e-learning's benefits (Admiraal and Lockhorst, 2009; Bielli and Klobas, 2003). Nevertheless, we still lack an integrative view of the determinants of e-learning adoption and assimilation in SMEs. This integrative view would pinpoint the interaction of different factors that are deemed antecedents of successful e-learning adoption and assimilation for SMEs, allowing them to seize the learning opportunities offered by new information technologies. Here, assimilation differs from adoption in that it refers to the breadth and depth with which a technology is used in an organization, that is, its "infusion" and "routinization" (Gallivan, 2001). E-learning assimilation is deemed very important as it is generally accepted that "the potential business value of IT applications cannot be fully realized until they are extensively assimilated in an organisation" (Liang, Saraf, Hu and Xue, 2007, p. 60).

Beginning with the previous abundant empirical literature on the adoption and assimilation of IT, including the literature that targets SMEs in particular (Botta-Genoulaz and Millet, 2006; McCole and Ramsey, 2005; Scupola, 2008; Tsikriktsis, Lanzolla, and Frohlich, 2004), and taking into account the peculiar features of e-learning in the context of SMEs, this study proposes an integrative framework of e-learning adoption and assimilation adapted to this context. This framework aims to be useful not only to e-learning researchers but eventually to 
SME managers, vocational training institutions, the e-learning industry, and regional or national economic development agencies dealing with the emerging challenges facing SMEs. It shows the key role played by the SME owner-manager's strategic orientation, first in the sense-making of technological and environmental factors related to the e-learning context, and second in the shaping of organizational competencies leading to e-learning adoption and assimilation.

This paper begins with a section on the state of e-learning usage in SMEs. The following section reviews the literature on IT adoption and assimilation factors that can be specifically applied to e-learning adoption and assimilation. We then integrate these factors within a research framework, and formulate a set of twenty propositions for future research.

\section{State of E-learning Usage in SMEs}

Perusal of the e-learning literature in SMEs leads one to conclude that the promises of a brilliant future have yet to materialize in reality. An analysis based on data gathered by the European Network for SME Research (ENSR) in 2002 (Hamburg and Hall, 2008) showed that no less than $59 \%$ of the SMEs surveyed had no formal training activity whatsoever; but what is perhaps the most revealing detail is that the "e-learning" category was not even mentioned in the survey. The ENSR survey measured usage of trade fairs, courses, study visits, job rotation, mentoring, professional literature, cooperation with consultants, internal meetings and "other activities", but not a word on e-learning. Hamburg and Hall (2008) added that only 7\% of the SMEs had used the Internet in the context of human resources management, a broad category likely to be dominated by recruiting rather than by training. 
The ARIEL project, concluded in December of 2005, is perhaps even more sobering. The final report (Beer et al., 2006) documents a multi-national research project funded by the European eLearning initiative. The report states that "[research partners] were practically unable to identify SMEs that would meet the EU criteria for an SME having practical experience with elearning. Various conferences, network meetings, and trade fairs on e-learning always seemed to exhibit the same SMEs as 'models of good practice' on the podium" (translated from German, cf. Hamburg et al., 2008, for a summary in English). Sambrook (2003) had a similar experience in North Wales. Despite using promising leads, such as the "Fast Growth Fifty", of the 146 SMEs contacted only nine had some experience with e-learning, five of which were e-learning providers.

Several reasons are offered to explain this state of affairs. Sambrook (2003) mentions lack of hardware, expertise, time and resources, difficulty in assessing the cost of e-learning and differences in language. Scheuermann and Reich (2002) found only a handful of Austrian SMEs to have had experience in e-learning. They report that the reasons for not relying on e-learning include lack of time, the fear of losing trained employees to other firms and the lack of infrastructure. In similar fashion, Bielli and Klobas (2003) found little enthusiasm for e-learning in a sample of Italian SMEs that had first-hand experience with this technology. Managers found e-learning products difficult to evaluate and not particularly likely to provide value for the money. Atwell (2003) in the final report of the European Centre for the Development of Vocational Training (CeDeFoP) writes that SMEs are deficient in training culture and computer infrastructures, that the market offers few quality learning objects and that it is not clear that the 
return on investment (ROI) for e-learning is positive. This author also notes the rise of blended learning.

A recent publication by Admiraal and Lockhorst (2009), looking at SME ownersmanagers' attitudes provides an important insight. Measuring attitudes towards the following seven concepts on five-point scales, namely technology for communication, technology for work, informal e-learning, formal e-learning, informal learning, formal learning and business networking, these authors report the lowest attitude scores for formal e-learning (2.3) and the highest towards informal e-learning (3.5).

\section{E-learning adoption and assimilation factors}

E-learning systems are closely related to IT. We refer to e-learning when the "learning procedure is involved with information and communication technologies" (Wang, 2011, p. 192). More broadly, e-learning is defined as "a tool that uses the computer network technology, primarily via electronic media, such as internet, intranets, extranets or many others, to deliver learning materials to users, and utilizes Web-based communication, collaboration, knowledge transfer and training to support users' active learning without the time and space barriers" (Cheng, 2011, p. 271). This tight relationship between e-learning and IT justifies the reliance on IT adoption and assimilation literature in order to understand e-learning adoption and assimilation antecedents.

Multiple previous studies have shown that IT adoption and assimilation in organizations are determined by numerous factors which can be put in one of the three categories of Tornatzky and Fleischer's (1990) technology-organization-environment (TOE) framework. Hence the process by which a firm adopts and implements technological innovations is influenced by the 
technological, organizational, and environmental contexts. Actually, many such contextual factors of IT adoption and assimilation have been studied in various contexts (SME vs. large enterprise, services vs. manufacturing sector, for a specific type of IT such as enterprise resource planning (ERP) systems. In the present study, we seek to identify those factors that are applicable to the adoption and assimilation of e-learning as a particular IT innovation, in the context of SMEs, and to highlight the specificity of these factors for such an IT and that particular context.

\subsection{Technology-related factors}

While the notion of IT covers a reality that is quite diversified and complex, the tendency to refer to it as if it was a monolithic reality can seriously limit, even jeopardize our comprehension of IT adoption and assimilation by business enterprises. For example, what similarity is there between adopting and assimilating e-mail technology on the one hand, and adopting and assimilating an ERP system on the other? In a previous study, de Jong, de Ruyter, and Lemmink (2003) found the antecedents of IT adoption to be notably different for standardized versus customized IT, and concluded on the need for managers "to discriminate between types of technology and fine-tune their IT adoption strategy to the specific type of IT concerned" (p. 177). Hence it is necessary here to address the specific technological aspects of e-learning.

In their study, Hsbollah and Idris (2009) found that among the perceived attributes of innovation (relative advantage, compatibility, complexity, trialability and observability as defined by Rogers, 2003), only two factors, that is, relative advantage and trialability, play a significant role in the e-learning adoption decision. For their part, Hung, Chen, and Lee (2009) identified an e-learning system's complexity, incompatibility, and cost as the three main technological barriers 
to the adoption of e-learning in hospitals. It has also been acknowledged that the lack of an adequate IT infrastructure would be a major drawback for the exploitation of e-learning in small firms (Admiraal and Lockhorst, 2009). Indeed, the lack of access to the latest equipment, software and connectivity is among the barriers to a satisfactory e-learning experience for small and micro-firms (Hardaker et al., 2007). In the same vein, among other hindrances that can delay e-learning adoption, Gascó, Llopis and González (2004) identified the cost (initial investment and permanent equipment update) and the heterogeneous and unconsolidated nature of the technology. Three main technological factors which are likely to affect the decision to adopt an elearning system seem to emerge from the literature: IT assets, e-learning technology complexity, and e-learning cost. The IT assets refer first to the availability of an IT infrastructure (hardware, software and network), and second to the compatibility of this infrastructure with the e-learning technology's offer.

\subsection{Organization-related factors}

In reviewing IT academic literature, one finds that a wide range of firm-level factors have the potential to enable IT adoption, including those relating to a firm's technological opportunism, technological orientation, organizational innovativeness, technology portfolio and absorptive capacity (Tsikriktsis et al., 2004), or factors related to top management support, organization culture, and characteristics of IS professionals (Tarafdar and Vaidya, 2007). As for e-learning adoption specifically, the organizational factors highlighted refer either to firm's characteristics such as size, sector, industrial relations system (unions) and single or multi-location establishment (Nisar, 2002), or to employees' characteristics such as level of education, rank of 
position, gender, competencies (computer and Internet self-efficacy, cognitive absorption) (Cheng, 2011; Nisar, 2002).

We first focus on the firm's size here, given that all the other organizational factors do not have the same connotation in a SME as in a large enterprise. The small firm is generally an extension of the beliefs, attitudes, and behaviours of the entrepreneur or owner-manager. This means that SMEs are strongly influenced by their owners' personal idiosyncrasies (MacGregor, 2004). Therefore, the beliefs, attitudes, and behaviours of the owner-manager will define the SME's learning culture. As the small firms' strategy, structure, and culture are embodied by their owner-managers, many organizational determinants of IT adoption can be considered as entrepreneurial determinants (Barba-Sánchez, Martínez-Ruiz, and Jiménez-Zarco, 2007). In the same vein, Hardaker et al. (2007, p. 137) made a plea for the "need for e-learning to be more personalised to the entrepreneurial nature of owner-managers" in small and micro-firms. We thus further analyze the three factors that appear critical for SMEs, namely the owner-manager's strategic orientation and competencies that determine e-learning adoption, and the employees' competencies that determine e-learning assimilation.

\subsubsection{SME owner-manager's strategic orientation}

It is generally in line with their particular needs and priorities that organizations adopt e-learning programs (Nisar, 2002). In the specific case of SMEs, these needs and priorities stem essentially from the strategic orientation of their owner-manager. A strategic orientation is "an indicator of the process developed to analyze and integrate new information, to coordinate decisions, to examine the evolution of environmental factors and to assess new projects" (Escribá-Esteve, 
Sánchez-Peinado, and Sánchez-Peinado, 2009, p. 582). SME owner-managers may differ in their strategic orientation, causing them to view their environments in different ways. In this regard, Miles and Snow's typology (Miles, Snow, Meyer, and Coleman, 1978) seems most appropriate to conceptualize and operationalize strategic orientation in the context of SMEs (O'Regan and Ghobadian, 2006), and indeed has been one of the most widely used constructs for ascertaining a firm's strategy in this context (Escribá-Esteve et al., 2009). This typology is based on how the firm responds to three major problems: the entrepreneurial problem (the organization's productmarket domain), the engineering problem (the choice of technologies and processes for production and distribution), and the administrative problems (formalization, rationalization and innovation in an organization's structure and policy processes).

Briefly, according to the Miles and Snow's typology, the firm's strategic orientations can be classified into four categories: prospector, defender, analyzer, and reactor. Roughly speaking, prospectors are deemed to be entrepreneurial, innovative and new opportunity-oriented: they tend to continuously widen their market with broad product lines, resort to multiple and flexible technologies, and adopt highly decentralized product structures; they also tend to emphasize flexibility and effectiveness over efficiency. In contrast, defenders are deemed to be more conservative, cautious, and oriented towards maintaining the firm's current competitive position in its market. Tending to focus on narrow and stable markets with a few products, to resort to a single core technology, and to adopt centralized functional structures, defenders are also likely to emphasize stability and efficiency over flexibility. Being a hybrid of a prospector and a defender, the analyzer is selective in pursuing new opportunities while seeking to maintain the firm's position in core markets. Having no well-defined strategy, the reactor's response to changes 
occurring in the firm's environment cannot be predicted a priori; this is why reactors are generally excluded from formal analysis (Mitchell and Zmud, 2006; Raymond and Bergeron, 2008).

\subsubsection{SME owner-manager's competencies}

According to Caldeira and Ward (2003), top-management perspectives and attitudes towards IT adoption and use, along with IT competencies (IT people and knowledge available) are the key determinants of the successful adoption and use of IT in SMEs. The determinants related to topmanagement can be linked to three sets of associated skills and competencies, namely technical IT skills, managerial IT skills, and business and general management skills (Wainwright, Green, Mitchell, and Yarrow, 2005). Amongst the last set, change management competencies would be very useful to deal with the human factors that can be detrimental to the adoption of e-learning, that is, factors such as fear of IT, resistance to learning and change, and demographic discrepancies between different stakeholders (gender, age). Indeed, McPherson and Nunes (2006) pointed out that different stakeholders may not willingly embrace e-learning technology, if they feel they have to do so to the detriment of their profession or to their career. The management team needs then to effectively manage the change process in order to gain common commitment through consensual debate and supporting strategies (McPherson and Nunes, 2006).

For Scupola (2008), the determinants of IT adoption related to top-management can be grouped into four main competencies: IT technical, IT vision, IT value and IT control competencies. In this author's study, with the notable exception of IT technical competency, all the other competencies at managerial level were found to be key determinants for the primary 
adoption of IT. However, the IT technical competency of the owner-manager should not be discarded in the context of SMEs, given the preponderant role the owner-manager plays in all major decisions. One would think that the difficulty in assessing the cost and the benefits of elearning (Sambrook, 2003), the little enthusiasm for e-learning (Bielli and Klobas, 2003), and the rather negative attitudes towards e-learning (Admiraal and Lockhorst, 2009) in SMEs may be related to a low level of technical e-learning knowledge among the owner-managers.

\subsubsection{SME employees' competencies}

Once the decision to adopt an e-learning system has been made at managerial level, a set of competencies at the employees' level are deemed necessary for its actual implementation and effective use. The provision of the technology by the firm's decision-makers, no matter how important and necessary it may be, is not a sufficient condition for e-learning to be actually used (Admiraal and Lockhorst, 2009). It is at the individual level that one will see if the e-learning technology adopted has been well assimilated, i.e. has become an integral part of the firm's culture and routines.

By nature, e-learning requires self-motivation and self-managed learning (Ettinger, Holton and Blass, 2006), so that e-learning assimilation hinges eventually on employees' willingness and capabilities. Employees' acceptance of the e-learning system is then an important issue for organizations if they have to use this system to solve learning and performance problems (Cheng, 2011). "Will staff be keen to learn on-line?" This question is deemed to be probably the most important of all (Ettinger et al., 2006, p. 145). Moreover, the ubiquitous availability of e-learning ("the rhetoric of any time, any place, any where") may be viewed 
unfavourably by some employees who may resent having to take time at home for work-related training (Servage, 2005, pp. 311-312).

Following a literature review, employees' competencies that play a significant role in IT assimilation were put into three broad categories for the purposes of this study, namely technical skills, learning capabilities, and business competencies. Technical skills refer both to tacit and explicit IT knowledge (Bassellier, Reich, and Benbasat, 2001). Amongst the four individual factors deemed to have a significant impact on employees' perception of e-learning, and therefore on their desire to accept it (Cheng, 2011), two are arguably related to their IT technical skills: computer self-efficacy and Internet self-efficacy. The two remaining factors, that is, cognitive absorption and learning goal orientation, are related to employees' learning capabilities. According to Cheng (2011, p. 275), computer self-efficacy refers to "the self-assessment of individual ability to apply computer skills to complete particular tasks"; Internet self-efficacy refers to "an individual's judgment of efficacy across multiple Internet application domains".

According to Cheng (2011, p. 275), cognitive absorption in an e-learning context is defined as "a state of deep involvement with the internet-based learning systems"; finally, learning goal orientation is conceptualized as "an achievement-oriented motivation via task learning process". As suggested in earlier studies, employees' e-learning capabilities may differ in accordance with individual characteristics such as age, gender, level of education, and personal or professional experiences (Garavan et al., 2010).

In contrast to technical skills, business competencies focus on domains of knowledge that are not specifically IT-related. They are defined as "the set of business and interpersonal 
knowledge and skills possessed by IT professionals that enable them to understand the business domain, speak the language of business, and interact with their business partners" (Bassellier and Benbasat, 2004). In this study however, when we refer to the notion of business competencies, we extend it to all professional categories of employees, including IT professionals if there are any in the firm.

\subsection{Environment-related factors}

A number of theories such as neo-institutional theory deny that technology adoption is the result of rational decisions or cognizant choices made by the firm (Tsikriktsis et al., 2004). IT adoption is thus rather seen as being a result of external or environmental pressures, and this would be particularly true of SMEs that are more susceptible to such pressures than large enterprises. The

environmental context factors found in the literature for e-learning systems adoption are regrouped under four main categories: social factors, institutional factors, competitive context, and sector or industry characteristics.

\subsubsection{Social Factors}

Social factors refer to "subjective norms on behavioural intention", that is, "the person's perception that salient social referents think he/she should or should not perform the behaviour in question" (Cheng, 2011, p. 277). Based on the extended technology acceptance model (TAM), Cheng's (2011) study found that social factors significantly affect user beliefs with regard to the e-learning system. More precisely, these factors influence the perceived usefulness of an elearning system which in turn directly affects attitudes towards using the system and intentions to use it. Even though this last study was based on a sample of employees, one can postulate the 
same conclusions may apply to SME owner-managers considering the adoption of e-learning in their organizations. Two categories of social factors were identified: external influence, and interpersonal influence. While external influences refer to the influence of mass media reports, expert opinions or other non-personal information, interpersonal influences refer to the influence of more personal or closer relations such as friends, family members, and colleagues.

\subsubsection{Institutional factors}

A firm's institutional context determines to some extent the pressures it will undergo to align itself to common practices often referred to as "best practices". But it is upon this same context that the firm depends for the resources it needs to adopt these practices. One can thus identify two main types of institutional factors that play a role in the adoption of e-learning: networking intensity and isomorphic pressures.

The decision to adopt and use IT innovation is made easier in a networked environment (MacGregor, 2004), as organizations within this environment will exert pressures towards IT innovation adoption. They will as well provide assistance to each other, allowing SMEs within the network to overcome their resource limitations (Mohnnak, 2007). Thus, for SMEs, the number and quality of connections to other organizations constitutes social capital that affects to a certain extent its IT adoption and assimilation capabilities (Gebauer, 2003). In particular, SME employees will get access to greater e-learning opportunities if their organizations are part of a chain of larger establishments (Nisar, 2002). Furthermore, a high level of collaboration and strong links within and among industries have been related to successful e-learning implementation (Uhomoibhi, 2006). 
Leading institutions such industry consortia, trade unions, national governments and training agencies will also be conducive to e-learning adoption by individual firms (Comacchio and Scapolan, 2004; Nisar, 2002). Confronted with the difficulty to evaluate the benefits to be gained from e-learning, organizations are likely to jump on "bandwagons" in this regard (Comacchio and Scapolan, 2004). Analyzing what they call "institutional bandwagon pressure" towards the adoption of e-learning, Comacchio and Scapolan (2004) distinguish three types of institutional pressures: coercive isomorphic pressures, mimetic isomorphic pressures, and normative isomorphisms. Coercive isomorphic pressures derive from political or financial influence of institutions operating in the labour market - unions, training associations, public organizations - and which may support and fund online training programs. When companies, facing uncertainty related to innovation, seek standardized solutions and adopt e-learning by imitating organizations considered as reference models, they succumb to mimetic isomorphic pressures. They succumb to a normative or regulatory isomorphism when their decision to embrace e-learning stems from the influence of the professional community to which belongs the staff in charge of training decisions. The notions of coercive, mimetic, and normative isomorphism are widely-referred to in institutional theory which mainly posits that organizational behaviours, such as innovation adoption, are to some extent driven by the need for organizational "legitimacy" (Liang et al., 2007).

\subsubsection{Competitive context}

Given ambiguity in their goals, in the means to achieve these goals and in their environment, organizations may have difficulty in ascertaining whether the IT innovation adopted by 
competitors will become a source of competitive advantage (Comacchio and Scapolan, 2004). In the case of e-learning systems, they are acknowledged as triggers of such advantage, deemed able to "create value, reduce costs, or achieve a combination of both" (Roffe, 2004, p. 404). SMEs may then decide to adopt e-learning systems by fear of being at a competitive disadvantage, and would thus be under bandwagon competitive pressures to adopt the same innovation as their competitors (Comacchio and Scapolan, 2004).

\subsubsection{Sector/industry characteristics}

Training Magazine (2004) reported the findings of a survey which found that the sector or industry in which a company operates is, with firm size, the major driver of e-learning adoption. A survey conducted in the UK (Young, 2002) also demonstrated significant differences in elearning adopters by sector, as "early adopters" were found in the IT/telecommunications sector, the adoption rate in this sector being the highest (61\%), followed by the education sector (57\%), and the financial services sector (51\%), with the manufacturing/industrial/retail sector (32\%) and the government sector (27\%) lagging behind.

The characteristics of the industry and the market in which a firm operates determine to some extent the imperatives that will apply to its technology adoption decisions. The level of skills required, the intensity of technology used, the pace of technological change, the abundance or shortage of qualified human resources and the need for renewable knowledge are factors that vary according to the nature of each industrial sector. These factors are deemed in one way or another to have an impact on learning needs in general, and on e-learning needs in particular. For instance, Nisar (2002) pointed out that the hospitals and health establishments, due to their 
greater probability of experiencing a shortage of skilled employees, would be more apt to consider e-learning solutions. One would surmise that such impact of sector/industrial characteristics on e-learning needs would also apply to SMEs. Collins, Buhalis and Peters (2003) contend that e-learning solutions may be valuable for SMEs in the tourism and hospitality sectors due to the high employee turnover rates in these sectors, and to the time constraints and workload of their managers that prevent them from attending conventional training sessions.

\section{Research framework and propositions}

Given the preceding considerations, we propose a research framework integrating technological context factors, organizational context factors, and environmental factors as antecedents of elearning adoption and assimilation in SMEs, as schematized in Figure 1.

Figure 1: E-learning adoption and assimilation framework for SMEs 


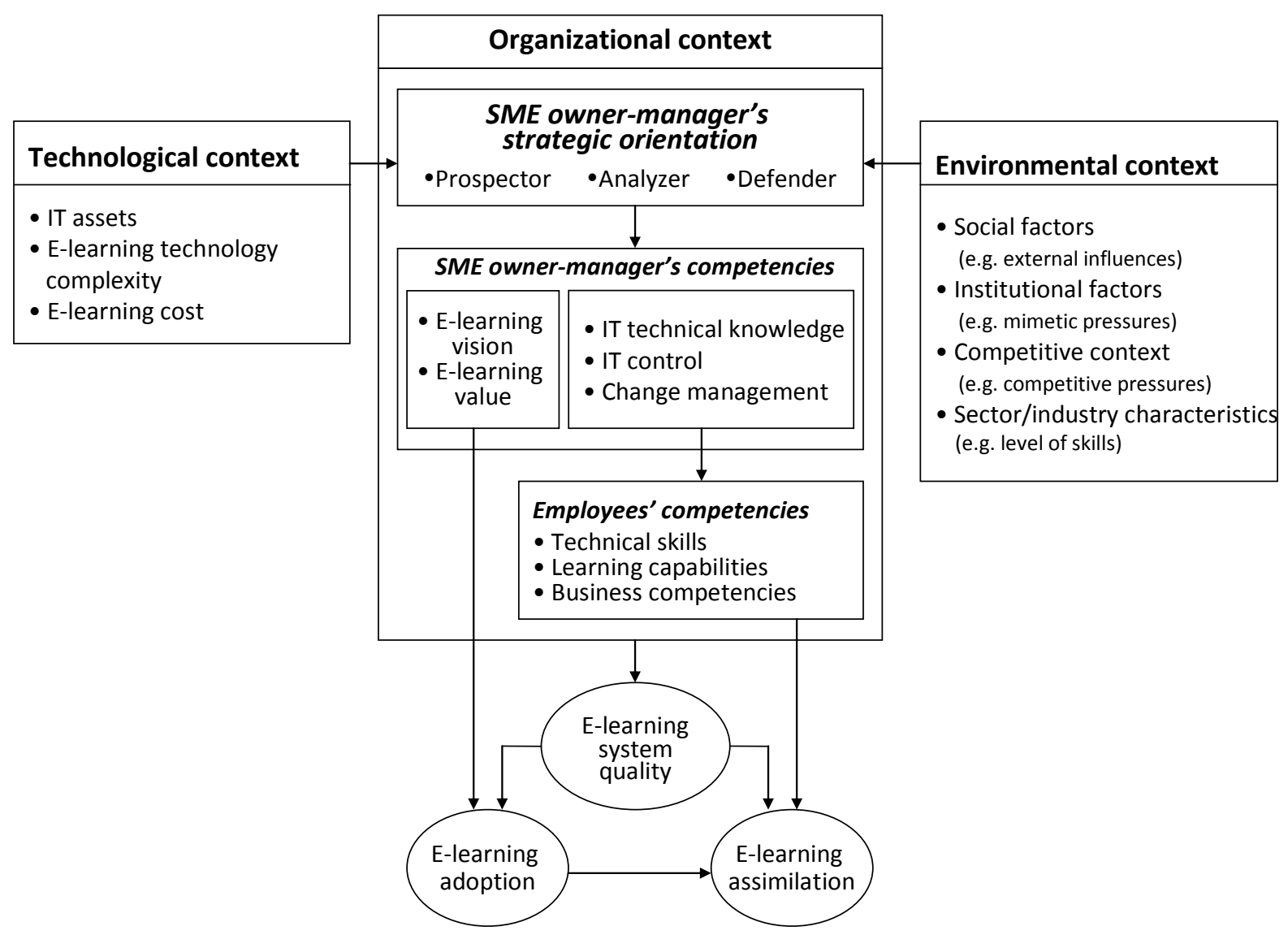

\subsection{The key role of the SME owner-manager's strategic orientation}

Among all organizational factors, there is reason to underline the particular role played by the owner-manager's strategic orientation. In the context of SMEs, organizational strategic outcomes and processes are a function of the managerial characteristics of the owner-manager. The SMEmanagement literature assumes that the owner-manager's strategic orientation plays a key role in all of the SME's major decisions (Aragón-Sánchez and Sánchez-Marín, 2005; Raymond and Bergeron, 2008). Strategy being the mediating force between the firm and its environment 
(Raymond and Bergeron, op. cit.), it is through the small business owner-manager's strategic orientation that one can understand the latter's sense-making of the technological and environmental contexts, that is, how he or she detects threats and opportunities. This sensemaking will affect the development of the owner-manager's competencies as well as his or her choices in regard to acquiring human resources and developing employees' competencies.

\subsubsection{Owner-manager's strategic orientation and technological context}

Considering that SMEs of the prospector strategic type are constantly in search of new opportunities, one expects these firms to be the first and the most numerous in adopting new IT, and to experiment with a greater number of technologies (Raymond and Bergeron, 2008). Being preoccupied by reinforcing their position in existing markets, defenders will be less apt than prospectors to innovate technologically. In matters of IT, the former will stick with technologies that have been proven useful in e-learning within their markets. For analyzer firms, as they sometimes behave as prospectors or as defenders depending upon the situation, an in-between position is assumed, thus the following proposition:

P1: Prospectors will have developed more IT assets (hardware, software, network) needed to adopt e-learning solutions than analyzers, and even more so than defenders.

From the literature, one perceives that the notion of IT complexity, rather than being an absolute technical characteristic, is more contingent upon the adopting organization. It refers to the relative perception of potential adopters as to the ease with which IT-related standards can be understood, and then be implemented and used (Alkraiji, Jackson, and Murray, 2010). There exists a negative relationship between the perceived complexity of e-learning technology and the 
firm's decision to adopt it (Hsbollah and Idris, 2009). Being most entrepreneurial, innovative and opportunity-oriented, prospectors are likely to perceive IT innovations as being less complex than analyzers and defenders. This would explain why, according to Mitchell and Zmud (2006), when it comes to technological investment patterns within an industry, prospectors are "first movers", while analyzers and defenders are found respectively among the early adopters and late adopters. These considerations lead to the following proposition:

P2: Prospectors will perceive e-learning technology as being less complex than analyzers, and even more so than defenders.

It has been noticed that the defenders' IT strategy emphasizes cost containment, while the prospectors' is based on flexibility and innovation (Sabherwal and Chan, 2001). Operating in stable markets and emphasizing resource efficiency and cost-cutting process improvements to maintain their base business (Di Benedetto and Song, 2003; Shortell and Zajac, 1990), defenders will be more sensitive to the cost of e-learning than prospectors, hence the following proposition:

P3: In their e-learning adoption process, defenders will be more restrained by the cost of e-learning technology than analyzers, and even more so than prospectors.

\subsubsection{Owner-manager's strategic orientation and environmental context}

\section{Strategic orientation and social factors}

Social influences may play a direct impact on both the attitude towards IT and the intention to adopt IT. Indeed, social factors have been found to significantly influence potential adopters of elearning systems (Cheng, 2011). SME owner-managers' beliefs, attitudes and intentions to use these systems are shaped by both interpersonal and external influences, the nature and the reach 
of these influences varying according to their strategic orientation. For instance, prospectors, being characterized by a constant scanning of their environment, are likely to be more affected by external influences than defenders whose scanning activities are more limited. As prospectors are more externally-oriented and defenders are more internally-oriented (O'Regan and Ghobadian, 2006), the following propositions ensue:

P4: In their e-learning adoption process, prospectors will be more affected by external influences than analyzers, and even more so than defenders.

P5: In their e-learning adoption process, defenders will be more affected by interpersonal influences than analyzers, and even more so than prospectors.

\section{Strategic orientation and institutional factors}

Institutional factors considered here are related to networking intensity and to isomorphic pressures. Networking intensity can be appreciated by heeding the nature of the networks in SMEs are engaged. A network can be broadly defined as "an integrated and co-ordinated set of ongoing economic and non-economic relations embedded within, among and outside business firms" (MacGregor, 2004, p. 65). It has been demonstrated that SMEs adopt particular network forms depending on their strategic orientation (Golden and Dollinger, 1993): prospectors, analyzers, and defenders are more likely to engage in confederate relationships, agglomerate/organic relationships, and conjugate relationships respectively. According to Jarratt (1998), confederate relationships refer to competitors with contractual agreements that synergize functional activities such as shared shipping costs, agglomerate relationships refer to competitors with no contractual arrangements such as trade organisations, organic relationships refer to 
traditional networking across industries such as board memberships or other voluntary organizations (indirect and non-contractual), and conjugate relationships refer to vertical linkages across the value chain such as buyer-supplier or subcontracting relationships. Considering that direct, "symbiotic" linkages (contracts based on mutual need) are stronger than indirect, "commensalistic" linkages (based on economic ends) (Audia, Freeman and Reynolds, 2006), the four types of networks can be ordered by decreasing order of networking intensity, that is, conjugate, confederate, organic and agglomerate networks. The following proposition can then be formulated:

P6: Defenders, tending to engage in conjugate networks, will be subjected to greater pressure and will receive greater support for e-learning adoption from their networking partners than prospectors who tend to engage in confederate networks, and even more so than analyzers who tend to engage in agglomerate and organic networks.

One can also surmise that defenders will be more subjected to isomorphic pressures, when compared to prospectors. Operating in stable markets, defenders are likely to develop long lasting relationships with institutions interested in their sector's or industry's development, and would thus be inclined to follow the latter's recommendation to adopt e-learning systems (coercive isomorphic pressures). In addition, defenders are late adopters of technological innovations for the most part. In order to reduce the uncertainty related to e-learning adoption, these firms should indeed adopt and use e-learning systems only after prospectors have done so (mimetic isomorphic pressures), the latter being the greater risk-takers and first movers in technological innovations. In similar fashion, greater normative (or regulatory) isomorphic pressures would be 
felt by defenders, when compared to prospectors, as latter adopt innovations without need for guidance from a standards community or reassurance from a professional community. The following proposition related to isomorphic pressures can thus be formulated:

P7: In their e-learning adoption process, defenders will be more affected by coercive, mimetic, and normative isomorphic pressures than analyzers, and even more so than prospectors.

\section{Strategic orientation and competitive context}

As in the case of institutional pressures, competitive pressure would also be felt more intensively by defenders than by prospectors. When it comes to adopting new technologies, defenders and prospectors are found to be at the two ends of a continuum, ranking respectively high and low in defensiveness, and low and high in proactiveness (Sabherwal and Chan, 2001). This means that while prospectors would likely adopt e-learning in order to exploit a possible opportunity, defenders would adopt them out of strategic necessity, that is, to prevent competitors who have already adopted this technology from gaining a competitive advantage, hence the following proposition:

P8: In their e-learning adoption process, defenders will be more affected by competitive pressure than analyzers, and even more so than prospectors.

\section{Strategic orientation and sector characteristics}

For Botta-Genoulaz and Millet (2006), the variation in the demand for IT infrastructure capabilities amongst industries will be determined by the level of information intensity and marketplace volatility, along with business unit strategies and strategy formation processes. But 
more specifically, e-learning systems are adopted to respond to training needs, and logically they will be appealing mainly for sectors in which those needs are high. These sectors are characterized either by the high level of skills required (e.g. the education sector), or by the intensive use of technology (e.g. the IT/telecommunications sector).

Differences in e-learning adoption and assimilation among individual firms within the same sector could be explained by strategies developed and implemented by SME ownermanagers. As prospectors, when compared to defenders, will likely have at their disposal more IT assets needed to adopt e-learning (cf. proposition 1), perceive e-learning to be less complex (cf. proposition 2), and be less sensitive to e-learning costs (cf. proposition 3), the following proposition can be made:

P9: Within the same sector, prospectors will show the highest e-learning adoption rates, whereas defenders will show the lowest e-learning adoption rates.

As both the SME's strategic orientation and the sector's characteristics must be taken into account, comparing for instance a prospector from sector A with a defender from sector B with regard to e-learning adoption would not be truly relevant. Such a comparison would only make sense if it is made between SMEs whose strategic orientation differs within the same sector (as in proposition 9) or between SMEs with the same strategic orientation but belonging to different sectors, as in the following propositions:

P10: Prospectors in high-technology sectors or in high-level skills sectors will show higher e-learning adoption rates than prospectors in low-technology sectors or in lowlevel skills sectors. 
P11: Analyzers in high-technology sectors or in high-level skills sectors will show higher e-learning adoption rates than analyzers in the low-technology sectors or in low-level skills sectors.

P12: Defenders in high-technology sectors or in high-level skills sectors will show higher e-learning adoption rates than defenders in the low-technology sectors or in low-level skills sectors.

With these propositions, we keep in mind that prospectors, analyzers, and defenders can coexist in one sector. In theory, one would expect a certain strategic profile to be more prevalent in a given sector, say, more prospectors in high-tech industries such as biotechnology and more defenders in low-tech industries such as furniture. However, empirical studies have yet to find a significant association between strategic profiles and industries (Sabherwal and Chan, 2001).

\subsection{The role of other organizational factors}

Two other sets of organizational factors, namely the owner-manager's competencies and employees' competencies play a role in both the e-learning adoption and e-learning assimilation processes. IT assimilation is defined as the degree to which the use of IT is integrated within business processes and becomes part of the activities associated with those processes (Fichman and Kemerer, 1997; Chatterjee, Grewal, and Sambamurthy, 2002). It has also been posited that the technological, organizational and environmental determinants of IT assimilation may differ from the determinants of IT adoption (Scupola, 2008; Wainwright et al., 2005). As is the case for IT in general, we postulate here that the SME owner-manager's competencies will play a positive role 
in e-learning adoption, whereas the SME employees' competencies will play a positive role in elearning assimilation.

\subsubsection{SME owner-manager's competencies and e-learning adoption}

In the context of SMEs, owner-managers will play a key-role in the decision to adopt e-learning systems. Their attitudes towards e-learning adoption will be shaped by their competencies, namely their e-learning vision, e-learning value, IT technical knowledge and IT control. A small business manager who displays the e-learning vision competency will understand the strategic importance of e-learning in business activities. This understanding will ultimately lead to the adoption of an e-learning system that is aligned with the business strategy. This is critical as "the learning system should be able to reflect the organization's learning needs, aligned with organizational mission and vision, job design, and reward system" (Wang, 2011, p. 195). But the vision competency, while necessary, is not sufficient. This general awareness of e-learning's usefulness must be translated into a specific appreciation of the business value that the firm may realize from its use of e-learning. Evolving from the IT vision competency to the IT value competency is not easy for some entrepreneurs (McGowan, Durkin, Allen, Dougan and Nixon, 2001). A strong IT value competency is likely to positively affect the owner-manager's perception of the quality of an e-learning system, which in turn will raise the likelihood of elearning adoption. Here, system quality refers to system functionality, system interactivity, system response and content quality (Cheng, 2011). Owner-managers whose e-learning vision and e-learning value competencies are strong are more likely to have a positive attitude toward elearning and thus to adopt this technology, leading to the following four propositions: 
P13: The SME owner-managers' e-learning vision and value will positively affect their perceived e-learning quality.

P14: The perceived e-learning quality will positively affect e-learning adoption.

P15: E-learning adoption rates will be higher in SMEs whose owner-managers have developed stronger e-learning vision and e-learning value competencies.

P16: SME owner-managers whose e-learning vision and e-learning value competencies are greater will adopt an e-learning system that is more aligned with their firm's business strategy.

Once the decision to adopt e-learning system has been made, its actual implementation and use will depend on the owner-manager's capacity to create facilitating conditions. These conditions include resource availability, technical support, user training, and removal of organizational barriers to the use of IT in general (Gallivan, Spitler and Koufaris, 2005; Neufeld, Dong, and Higgins, 2007) and e-learning systems in particular. Three main competencies will affect the capacity of the owner-manager to create facilitating conditions: IT technical knowledge, IT control, and change management. The owner-managers' IT technical knowledge, especially in the context of SMEs, will allow them to correctly ascertain the technical competencies required of employees, and the IT control competency will allow them not only to dedicate appropriate resources, but also to foster the effective exploitation of e-learning in their firms through appropriate IT governance mechanisms (Alaeddini and Kardan, 2010). Change management competencies will allow them to effectively deal with resistance to change and with 
other difficulties related to the technology adoption process. The following propositions can thus be stated:

P17: SME owner-managers whose IT technical knowledge, IT control, and change management competencies are stronger will create more facilitating conditions for elearning assimilation.

P18: SME owner-managers whose IT technical knowledge, IT control, and change management competencies are stronger will foster stronger competencies among their employees.

\subsubsection{Employees' competencies and e-learning assimilation}

In their study of large enterprises, Armstrong and Sambamurthy (1999) found that the IT knowledge of senior business executives had no influence on IT assimilation. According to Scupola (2008), this seems to be also true for SMEs, as this author found the competencies of employee (rather than the IT competencies of managers) to significantly influence the assimilation of IT in the firm. As previously mentioned, these competencies can be roughly grouped into three broad categories, that is, IT technical skills, learning capabilities, and business competencies.

As technology-related concerns in the context of distance learning may constitute constraints or barriers to participation in e-learning through their impact on self-efficacy and motivation to learn (Garavan et al., 2010), employees lacking sufficient technical IT skills may be less willing to resort to e-learning. Workplace learning aims at acquiring "from basic skills to high technology and management practice that are immediately applicable to workers' jobs, 
duties, and roles" (Wang, 2011, p. 192). Employees with stronger learning capabilities and stronger business competencies are more likely to discover the applicability, if any, of e-learning contents to their organizational tasks. They are likely to positively perceive e-learning system quality. The last two research propositions can then be stated as follows:

P19: The employees' IT technical skills, learning capabilities, and business competencies will positively affect their perceived e-learning system quality.

P20: SMEs whose employees demonstrate stronger IT technical skills, learning capabilities, and business competencies will achieve higher levels of e-learning assimilation.

\section{Conclusion}

It has been underlined that neither the economic-rational nor the technical-rational perspectives can by themselves explain the adoption of e-learning solutions, let alone explain e-learning's effectiveness in the workplace (Comacchio and Scapolan, 2004; Wang, 2011). The economic and technical aspects of e-learning systems may be quite important and deserve to be studied, but other organizational or environmental factors should not be ignored. The research framework for e-learning adoption and assimilation in SMEs proposed here is predicated upon the interaction of technology-related, organization-related and environment-related determinants. This framework highlights the predominance of organizational factors over technological and environmental factors.

We have proposed that technological and environmental factors do not affect directly the adoption and assimilation of e-learning systems as most often hypothesized in previous IT 
studies; they have an indirect influence, that is, through the effect they may have upon the organizational factors. These organizational factors play a critical role in the adoption and assimilation of e-learning. We emphasize the critical role of the SME's owner-manager in capturing, interpreting and reacting to signals emanating from the technological and environmental contexts. The twenty propositions resulting from these considerations are based on the literature and could thus serve as initial hypotheses in empirical research.

While this paper is theoretical, it suggests a frame of reference to managers contemplating an e-learning program by highlighting key adoption and assimilation factors in the specific context of SMEs. Referring to the framework, managers would be, for instance, more aware of their own biases in technological and environmental sense-making, and of the influence of these biases upon the development of their competencies as well as their employees' competencies with regard to e-learning adoption and assimilation. If these managers are considering adopting elearning solutions, they would be aware of the main competencies required for them and their employees to assimilate such an innovation.

The proposed research framework could also be used as conceptual foundation and methodological core to develop a measure instrument for the organizational readiness and strategic alignment of SMEs considering e-learning adoption and wanting to evaluate their use of this technology. Such an instrument should provide reliable and actionable insights to SMEs managers and e-learning practitioners interested in the SME market. For instance, the framework suggests to trainers, to the e-learning industry, and to SME support and development agencies that they must adapt their approach and e-learning offer to the conditions prevailing in targeted 
SMEs. Otherwise stated, the "one-size-fits-all" approach/offer would not be effective. The SME support and development agencies, for instance, will have to take into account the strategic profile of owner-managers in order to customize their development of e-learning tools targeted to SMEs and their leaders.

With regard to future research, given that e-learning is naturally related to training activities, relevant pedagogical factors could be included in the framework. For instance, it seems that the e-learning systems offered to employees of small and micro-firms are not compatible with their learning styles (Hardaker et al., 2007). Technology-related determinants of e-learning assimilation, such as the quality of the learning interface, should then come more into play.

\section{References}

Admiraal, W. and Lockhorst, D. (2009). E-Learning in small and medium-sized enterprises across Europe: Attitudes towards technology, learning and training. International Small Business Journal, 27(6), 743-767.

Alaeddini, M. and Kardan, A.A. (2010). E-learning governance: Towards an applicable framework. $2^{\text {nd }}$ International Conference on Education Technology and Computer, 3, 529-533.

Alkraiji, A., Jackson, T. and Murray, I. (2010). Identifying and modelling the critical success factors that affect the adoption of health information technology related standards. European, Mediterranean \& Middle Eastern Conference on Information Systems, April 12-13, Abu Dhabi, UAE.

Aragón-Sánchez, A. and Sánchez-Marín, G. (2005). Strategic orientation, management characteristics, and performance: A study of Spanish SMEs. Journal of Small Business Management, 43(3), 287-308.

Armstrong, C. P. and Sambamurthy, V. (1999). Information technology assimilation in firms: The influence of senior leadership and IT infrastructures. Information Systems Research, 10(4), 304-327.

Attwell, G. (2003). The Challenge of E-learning in Small Enterprises - Issues for Policy and Practice in Europe. European Center for the Development of Vocational Training, Luxembourg: Office for Official Publications of the European Communities. 
Audia, P. G., Freeman, J. and Reynolds, P. D. (2006). Organizational foundings in community context: Instruments manufacturers and their interrelationship with other organizations. Administrative Science Quarterly, 51, 381-419.

Barba-Sánchez, V., Martínez-Ruiz, M. d. P. and Jiménez-Zarco, A. I. (2007). Drivers, benefits and challenges of ICT adoption by small and medium sized enterprises (SMEs): A literature review. Problems and Perspectives in Management, 5(1), 103-114.

Bassellier, G. and Benbasat, I. (2004). Business competence of information technology professionals: Conceptual development and influence on IT-Business partnerships. MIS Quarterly, 28(4), 673-694.

Bassellier, G., Reich, B. H. and Benbasat, I. (2001). Information technology competence of business managers: A definition and research model. Journal of Management Information Systems, 17(4), 159-182.

Beer, D., Hamburg, I. and Paul, H. (2006). IAT-Report: Wissenschaftszentrum NordrheinWestfalen Kulturwissenschaftliches Institut.

Bell, M., Martin, G. and Clarke, T. (2004). Engaging in the future of e-learning: a scenariosbased approach. Education + Training, 46(6), 296-307.

Bielli, P. and Klobas, J. E. (2003). Bielli, P. and Klobas, J. E. (2003). E-learning and SMEs: Do demand and supply speak the same Language? $11^{\text {th }}$ European Conference on Information Systems, Milan.

Botta-Genoulaz, V. and Millet, P.-A. (2006). An investigation into the use of ERP systems in the service sector. International Journal of Production Economics, 99(1-2), 202-221.

Caldeira, M. M. and Ward, J. M. (2003). Using resource-based theory to interpret the successful adoption and use of information systems and technology in manufacturing small and medium sized enterprises. European Journal of Information Systems, 12(2), 127-141.

Caskey, K. (2007). Supporting SME e-commerce migration through blended e-learning. Journal of Small Business and Enterprise Development, 14(4), 670-688.

Chatterjee, D., Grewal, R. and Sambamurthy, V. (2002). Shaping up for e-commerce: Institutional enablers of the organizational assimilation of web technologies, MIS Quarterly, 26(2), 65-89.

Cheng, Y.-M. (2011). Antecedents and consequences of e-learning acceptance. Information Systems Journal, 21, 269-299.

Collins, C., Buhalis, D. and Peters, M. (2003). Enhancing SMTEs' business performance through the Internet and e-learning platforms. Education + Training, 45(8/9), 483-494.

Comacchio, A. and Scapolan, A. (2004). The adoption process of corporate e-learning in Italy. Education + Training, 46(6), 315-325.

de Jong, A., de Ruyter, K. and Lemmink, J. (2003). The adoption of information technology by self-managing service teams. Journal of Service Research, 6(2), 162-179. 
Di Benedetto, C. A. and Song, M. (2003). The relationship between strategic type and firm capabilities in Chinese firms. International Marketing Review, 20(5), 514-533.

Escribá-Esteve, A., Sánchez-Peinado, L. and Sánchez-Peinado, E. (2009). The influence of top management teams in the strategic orientation and performance of small and mediumsized enterprises. British Journal of Management, 20(4), 581-597.

Ettinger, A., Holton, V. and Blass, E. (2006). E-learner experiences: key questions to ask when considering implementing e-learning. Industrial and Commercial Training, 38(3), 143147.

Fichman, R.G. and Kemerer, C.F. (1997). The assimilation of software process innovations: An organizational learning perspective. Management Science, 43(10), 1345-1363.

Gallivan, M. J. (2001). Organizational adoption and assimilation of complex technological innovations: Development and application of a new framework. Database for Advances in Information Systems, 32(3), 51-85.

Garavan, T. N., Carbery, R., O’Malley, G. and O’Donnell, D. (2010). Understanding participation in e-learning in organizations: A large-scale empirical study of employees. International Journal of Training and Development, 14(3), 155-168.

Gascó, J. L., Llopis, J. and González, M. R. (2004). The use of information technology in training human resources: An e-learning case study. Journal of European Industrial Training, 28(5), 370-382.

Gebauer, M. (2003). Information systems on human capital in service sector organizations. New Library World, 104(1184/1185), 33-41.

Golden, P. A. and Dollinger, M. (1993). Cooperative alliances and competitive strategies in small manufacturing firms. Entrepreneurship Theory and Practice, 17(4), 43-56.

Hamburg, I. and Hall, T. (2008). Informal learning and the use of Web 2.0 within SME training strategies. eLearning Papers, 11, available at www.elearningpapers.eu.

Hamburg, I., Engert, S., Anke, P. and Marin, M. (2008). Improving e-learning 2.0-based training strategies of SMEs through communities of practice. Proceedings of the SIMPEL Conference, April, available at http://www.simpel-net.eu/docs/innsbruck.pdf.

Hardaker, G., Dockery, R. and Sabki, A. (2007). Learning styles inequity for small to micro firms (SMFs): Social exclusion through work-based e-learning practice in Europe. Multicultural Education \& Technology Journal, 1(2), 126-140.

Hsbollah, H. M. and Idris, K. M. (2009). E-learning adoption: the role of relative advantages, trialability and academic specialisation. Campus - Wide Information Systems, 26(1), 5470 .

Hung, S.-Y., Chen, C. C. and Lee, W.-J. (2009). Moving hospitals toward e-learning adoption: An empirical investigation. Journal of Organizational Change Management, 22(3), 239256. 
Jarratt, D. G. (1998). A strategic classification of business alliances: A qualitative perspective built from a study of small and medium-sized enterprises. Qualitative Market Research: An International Journal, 1(1), 39-49.

Liang, H., Saraf, N., Hu, Q. and Xue, Y. (2007). Assimilation of enterprise systems: The effect of institutional pressures and the mediating role of top management. MIS Quarterly, 31(1), 59-87.

Long, L. K. and Smith, R. D. (2004). The role of Web-based distance learning in HR development. Journal of Management Development, 23(3), 270-284.

MacGregor, R. C. (2004). Factors associated with formal networking in regional small business: Some findings from a study of Swedish SMEs. Journal of Small Business and Enterprise Development, 11(1), 60-74.

McCole, P. and Ramsey, E. (2005). A profile of adopters and non-adopters of eComemerce in SME professional service firms. Australasian Marketing Journal, 13(1), 36-48.

McGowan, P., Durkin, M. G., Allen, L., Dougan, C. and Nixon, S. (2001). Developing competencies in the entrepreneurial small firm for use of the Internet in the management of customer relationships. Journal of European Industrial Training, 25(2-3-4), 126-136.

McPherson, M. and Nunes, M. B. (2006). Organisational issues for e-learning: Critical success factors as identified by $\mathrm{HE}$ practitioners. International Journal of Educational Management, 20(7), 542-558.

Miles, R. E., Snow, C. C., Meyer, A. D. and Coleman Jr., H. J. (1978). Organizational strategy, structure, and process. Academy of Management Review, 3(3), 546-562.

Mitchell, V. L. and Zmud, R. W. (2006). Endogenous adaptation: The effects of technology position and planning mode on IT-enabled change. Decision Sciences, 37(3), 325-355.

Mohnnak, K. (2007). Innovation networks and capability building in the Australian hightechnology SMEs. European Journal of Innovation Management, 10(2), 236-251.

Moon, S., Birchall, D., Williams, S. and Vrasidas, C. (2005). Developing design principles for an e-learning programme for SME managers to support accelerated learning at the workplace. Journal of Workplace Learning, 17(5/6), 370-384.

Neufeld, D. J., Dong, L. and Higgins, C. (2007). Charismatic leadership and user acceptance of information technology. European Journal of Information Systems, 16(4), 494-510.

Nisar, T. M. (2002). Organisational determinants of e-learning. Industrial and Commercial Training, 34(7), 256-262.

O'Regan, N. and Ghobadian, A. (2006). Perceptions of generic strategies of small and medium sized engineering and electronics manufacturers in the UK: The applicability of the Miles and Snow typology. Journal of Manufacturing Technology Management, 17(5), 603-620. 
Raymond, L. and Bergeron, F. (2008). Enabling the business strategy of SMEs through ebusiness capabilities: A strategic alignment perspective. Industrial Management \& Data Systems, 108(5), 577-595.

Roffe, I. (2004). E-learning for SMEs: Competition and dimensions of perceived value. Journal of European Industrial Training, 28(5), 440-455.

Rogers, E.M. (2003) Diffusion of Innovations, $5^{\text {th }}$ edition, New York: The Free Press.

Sabherwal, R. and Chan, Y. E. (2001). Alignment between business and IS strategies: A study of prospectors, analyzers, and defenders. Information Systems Research, 12(1), 11-34.

Sambrook, S. (2003). E-learning in small organisations. Education + Training, 45(8/9), 506-516.

Scheuermann, F. and Reich, K. (2002). E-learning in Austrian SMEs: Innsbruck: Institute for Future Studies.

Scupola, A. (2008). Conceptualizing competences in E-services adoption and assimilation in SMEs. Journal of Electronic Commerce in Organizations, 6(2), 78-91.

Servage, L. (2005). Strategizing for workplace e-learning: some critical considerations. Journal of Workplace Learning, 17(5), 304-317.

Shortell, S. M. and Zajac, E. J. (1990). Perceptual and archival measures of Miles and Snow's strategic types: A comprehensive assessment of reliability and validity. Academy of Management Journal, 33(4), 817-832.

Tarafdar, M. and Vaidya, S. D. (2007). Information technology adoption and the role of organizational readiness: The case of an Indian bank. Journal of Cases on Information Technology, 9(3), 27-49.

Tornatzky, L. G. and Fleischer, M. (1990). The Processes of Technological Innovation: Lexington Books, Lexington, Massachusetts.

Training Magazine. (2004). Size and sector determine e-learning take-up. Training Magazine, November, 5.

Tsikriktsis, N., Lanzolla, G. and Frohlich, M. (2004). Adoption of e-processes by service firms: An empirical study of antecedents. Production and Operations Management, 13(3), 216229.

Uhomoibhi, J. O. (2006). Implementing e-learning in Northern Ireland: prospects and challenges. Campus-Wide Information Systems, 23(1), 4-14.

Wainwright, D., Green, G., Mitchell, E. and Yarrow, D. (2005). Towards a framework for benchmarking ICT practice, competence and performance in small firms. Performance Measurement and Metrics, 6(1), 39-52.

Wang, M. (2011). Integrating organizational, social, and individual perspectives in Web 2.0based workplace e-learning. Information Systems Frontiers, 13(2), 191-205. 
Young, K. (2002). Is e-learning delivering ROI? Industrial and Commercial Training, 34(2), 5461. 